\title{
Fluid and lithology discrimination of Amangi hydrocarbon field of the Niger Delta using Lambda-Mu-Rho technique
}

\author{
Sonny Inichinbia ${ }^{1}$, Peter O. Sule ${ }^{2}$, Aminu L. Ahmed ${ }^{2}$, Halidu Hamza ${ }^{2}$ and \\ Lucky M. Omudu ${ }^{3}$ \\ ${ }^{1}$ Department of Physics, Ahmadu Bello University, Zaria, Nigeria \\ ${ }^{2}$ Department of Geology, Ahmadu Bello University, Zaria \\ ${ }^{3}$ Shell petroleum Development Company of Nigeria Limited, Port Harcourt, Nigeria
}

\begin{abstract}
Lambda-Mu-Rho analysis was used to identify gas sands of two reservoirs (H1000 and H4000) in Amangi field of the Nigerian Delta. The main objective of this study was to provide a detailedprediction of the properties of these two Tertiary reservoirs using thistechnique of gas sand identification. This was possible because each lithology has a different rock properties response subject to fluid content and mineral properties. The basic impedances of both compressional and shear waves from the angle stacks were determined for the two reservoirs andLambda-Rho $(\lambda \rho)$ and $M u-R h o(\mu \rho)$ calculated. In the gas sand, the low incompressibility $(\lambda)$ of gas combined with the high rigidity $(\mu)$ of sand resulted in a low $\lambda \rho$ value, $\left(1.0 \times 10^{13} \mathrm{~kg}^{2} / \mathrm{m}^{4} \mathrm{~s}^{2}-2.0 \times 10^{13}\right.$ $\left.\mathrm{kg}^{2} / \mathrm{m}^{4} \mathrm{~s}^{2}\right)$ and a high $\mu \rho$ response, $\left(1.4 \times 10^{13} \mathrm{~kg}^{2} / \mathrm{m}^{4} \mathrm{~s}^{2}-2.0 \times 10^{13} \mathrm{~kg}^{2} / \mathrm{m}^{4} \mathrm{~s}^{2}\right)$. The $V_{p} / V_{s}$ ratio ranges 1.6 tol.8 for gas sand and 1.8 to 2.4 for shale. Equipped with this understanding from petrophysics, a high degree of discriminationoflithologies and fluidswas achieved. The gas sands, brine sands and shaleswere characterized successfully by the $\lambda \rho-\mu \rho$ space.
\end{abstract}

Keywords: Inversion,Lambda-Rho, Mu-Rho, P-impedance, S-impedance,

\section{Introduction}

There are exploration challenges in the data set of this field, such as the discrimination of hydrocarbon bearing sands from shales and more importantly, the separation of gas sands from brine saturated sandstones. In order to address these issues, new 3D prestackseismic data were acquired with long offset cable and high fold of coverage giving better resolution and structural interpretation across the reservoirs of interest.The current challenge is therefore; to use the new processed anisotropic 3D prestack seismic data to derisk the reservoirs' variability and heterogeneity and select location for new development wells.

The aim of this work is to use rock physics analysis of well log data and $\lambda-\mu-\rho$ attributes from AVO inversion of the anisotropic 3D seismic data to discriminate the lithology and fluid properties. The results from prestack simultaneous inversion of the angle stacks were included to illustrate the utility of these attributes in identifying the gas reservoirs, since P-impedance alone could not discriminate the gas sands from from shale.

Lambda-Mu-Rho $(\lambda-\mu-\rho)$ technique is an AVO inversion in which prestack seismic CMP gathers are inverted to extract data volumes of Lamé's elastic rock parameters lambda $(\lambda)$ and mu $(\mu)$ combined with density $\rho$ in the form of $\lambda \rho$ and $\mu \rho$. The use of the Lame parameters for reservoir fluids and lithology detection was introduced by [1]. The $\lambda \rho$ is the multiplication of the incompressibility by the density and $\mu \rho$ is the multiplication of the rigidity by the density. These two parameters were obtained from AVO inversion by using the moduli $(\lambda$ and $\mu)$ and density relationship to impedance.

AVO analysis requires crossplotting P-impedance (Zp), S-impedance $(\mathrm{Zs})$ or $(\lambda \rho),(\mu \rho)$ for fluid and lithology discrimination, with $\lambda \rho, \mu \rho$ showing a significant advantage in isolating both lithologic (sand, shale) and gas zones. Thus, AVO analysis of prestack seismic data has made several advances by combining AVO attributes and geology, petrophysical properties of the rocks and fluids.

The $\lambda-\mu-\rho$ analysis is one example of how interpreters are using advanced AVO analysis to identify hydrocarbons and reservoir rocks. It requires crossplotting or interpretation of multiple volumes of data to correctly interpret lithologies and fluids. We used petrophysics to scale the Lambda-Rho and Mu-Rho volumes, lithology volumes were based on rock properties and AVO, through crossplot analysis of the $\lambda-\mu-\rho$ volumes.

\section{Location and Geology of the study area}

Amangi Field is located $70 \mathrm{~km}$ northwest of Port Harcourt within licence OML 21 of the Niger Delta of southern Nigeria as shown in Fig. 1. The Niger Delta lies between latitudes $4^{\circ} \mathrm{N}$ and $6^{\circ} \mathrm{N}$ and longitudes $3^{\circ}$ $\mathrm{E}$ and $9^{\circ} \mathrm{E}$. The Niger Delta is a coarsening upward regressive sequence of Tertiary clastic sediments which is divided into three lithostratigraphic units representing prograding depositional facies. These units are distinguished mostly on the basis of sand-shale ratios as follows: the Akata Formation at the base of the delta, 
Agbada Formation overlying the Akata Formation and the Benin Formation overlying the Agbada Formation. Knowledge and understanding of the geology of the Niger Delta is gotten from the detailed works of $[2,3,4,5,6,7,8]$.

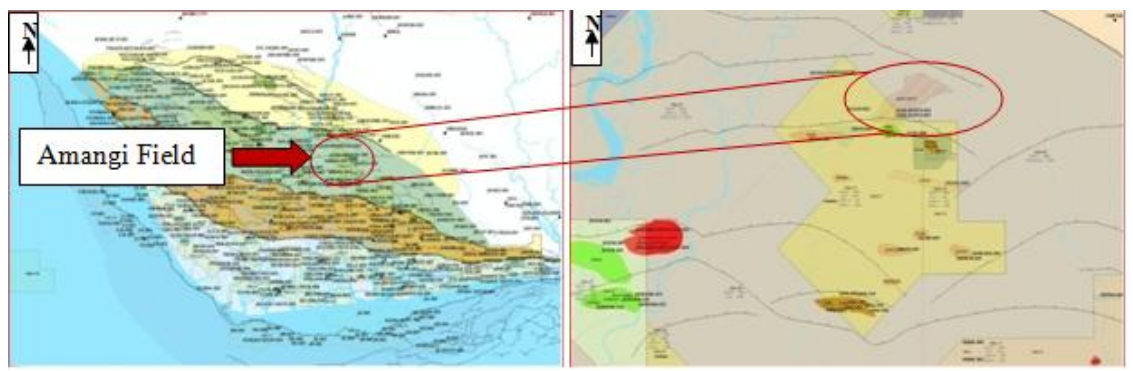

Figure 1. Map of the Niger Delta showing the study area. The encircled portion is the location of Amangi Field showing well locations. (Source: Shell Petroleum Development Company of Nigeria Ltd.).

The structure of Amangi field is a complex collapsed crest, rollover anticline, predominantly shore face and channel deposits with distinctive coarsening upward characteristics. Hydrocarbons in the field are found between 7,300 ftss and 12,600 ftss in a predominantly deltaic sequence consisting of alternating sands, silts and shale layers [9].

\section{Well log data}

Six wells have been drilled on the field. All the wells have at least a basic log suite to support a basic petrophysical evaluation. Two gas bearing sandstone reservoirs H1000 and H4000 have been encountered in five wells in the Tertiary Agbada Formation of Amangi field of the Nigerian Delta. Extensive logging dataset were acquired and displayed in Table 1. The location of some of the wells in the study area is shown in Fig. 2

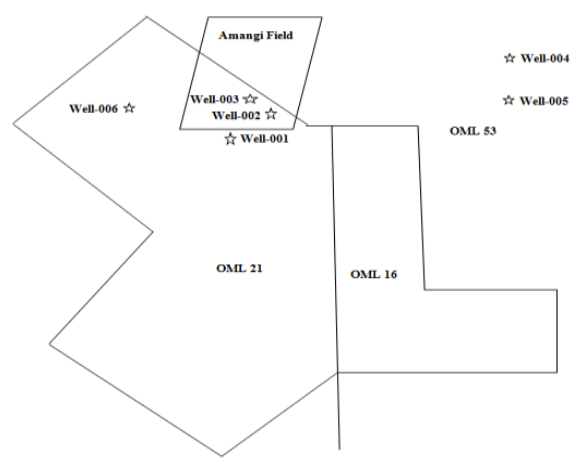

Figure 2.OML map of the study area showing the locations of the wells used in this study. Four out of a total of six wells are located in OML 21 whereas the rest two wells are sited in OML 53.

Logs from five wells were available for this work and they are displayed in Table 1.

Table 1. Some wells in Amangi Field showing suite of logs in each well. Only well-002 has a complete suite of good quality logs in the area, needed for this work.

\begin{tabular}{|c|c|c|c|c|c|c|c|c|}
\hline Well & $\begin{array}{l}\text { GR } \\
\text { (API) }\end{array}$ & $\begin{array}{l}\text { CALL. } \\
\text { (inches) }\end{array}$ & $\begin{array}{l}\text { RESIS. } \\
(\Omega \mathrm{m})\end{array}$ & $\begin{array}{l}\text { DEN. } \\
\left(\mathrm{g} / \mathrm{cm}^{3}\right)\end{array}$ & $\begin{array}{l}\text { SONIC } \\
(\mu \mathrm{s} / \mathrm{ft})\end{array}$ & $\begin{array}{l}\text { PRESS. } \\
\text { (psi) }\end{array}$ & FIT & Checkshot(ms) \\
\hline $\begin{array}{l}\text { Well- } \\
001\end{array}$ & YES & YES & YES & NO & YES & NO & NO & YES \\
\hline $\begin{array}{l}\text { Well- } \\
002\end{array}$ & YES & YES & YES & YES & YES & YES & YES & YES \\
\hline $\begin{array}{l}\text { Well- } \\
003\end{array}$ & YES & YES & YES & YES & YES & YES & NO & NO \\
\hline $\begin{array}{l}\text { Well- } \\
004\end{array}$ & YES & YES & YES & YES & YES & NO & NO & NO \\
\hline $\begin{array}{l}\text { Well- } \\
005\end{array}$ & YES & YES & YES & YES & YES & NO & NO & NO \\
\hline
\end{tabular}


Fig.3 shows the logs of well-002. This well was chosen among the five wells because it has the complete suite of $\log$ s for this study. The well log measurements include gamma ray, neutron, sonic, caliper, compressional velocity $\left(\mathrm{V}_{\mathrm{p}}\right)$, shear wave velocity $\left(\mathrm{V}_{\mathrm{s}}\right)$, and density $(\rho)$, as well as estimates of lithology and pore fluid content(volume fractions of shale, quartz, gas, and water components) for well-002.

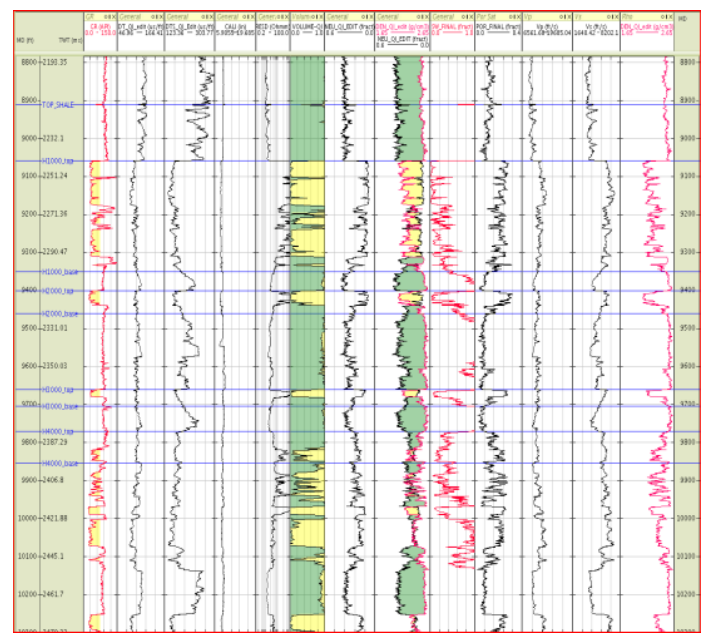

Figure 3.Wireline log signatures obtained in the area of study. Gamma ray, sonic, caliper, resistivity, volume shale, neutron, porosity, $V_{p}, V_{s}$ and density logs from one of the wells (Well-002) used in this study. The thick gas reservoir is characterized by higher resistivities and neutron-density crossover.

\section{Seismic data}

A 3D anisotropic seismic data was acquired over this field by shell Petroleum Development Company (SPDC) of Nigeria Limited between 2008 and 2010. The data were processed by the same company in 2011ensuringtrue amplitudes were preserved. Fig. 4 shows the three common angle stacks generated from the seismic data, namely, the near angles stack $\left(0^{\circ}-10^{\circ}\right)$, mid angles stack $\left(11^{\circ}-20^{\circ}\right)$, and far angles stack $\left(21^{\circ}-\right.$ $30^{\circ}$ )to provide non overlapping common angle stacked sectionsfor inversion for reservoir properties. The three stacked sections were migrated with afrequency-wavenumber time migration algorithm to collapsethe diffractions and properly position the events.These three migrated sections were subsequently inverted simultaneously to obtain estimated volume distributions of the layer properties, namely, P-impedance, Simpedance, and density.

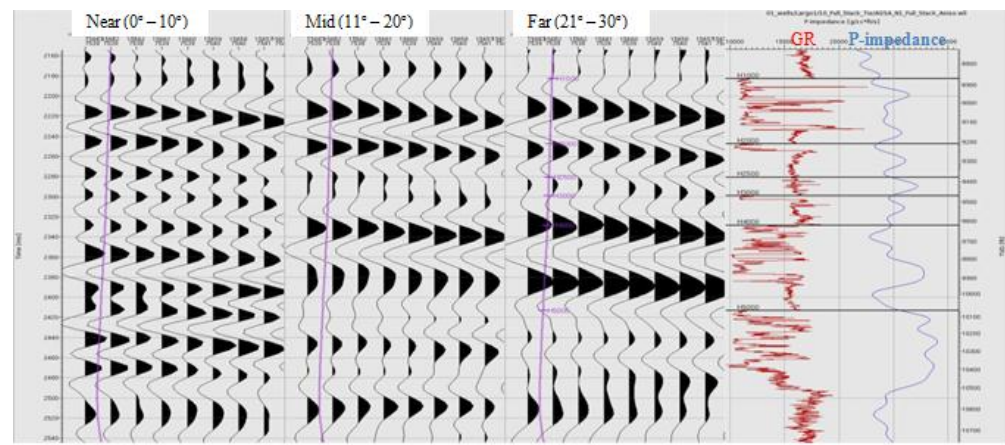

Figure 4. AVO effect on a flattened synthetic CMP gather caused by the presence of gas in the reservoir sands. The Near $\left(0^{\circ}-10^{\circ}\right)$, Middle- Mid $\left(11^{\circ}-20^{\circ}\right)$ and Far $\left(21^{\circ}-30^{\circ}\right)$ angle stacks used in this study. Using the stacking velocities, the offset gathers were converted to angle gathers using angles between $0^{\circ}$ and $30^{\circ}$.

The near angles amplitude value is different from the amplitude measured on the far offset trace.

\section{Methodology}

We simultaneously inverted multiple angle stacks to transform P-wave offset seismic reflection data to P-impedance and S-impedance volumes. These impedance volumes were interpreted separately and then combined to estimate other geophysical parameters, such as the Lame' parameters, notably, Lambda and $\mathrm{Mu}$, respectively. These attributes optimally discriminated between facies and fluids in the study area. From well log analysis, we discovered that reservoir sandstones have lower Lambda (incompressibility) and higher Mu (rigidity) than the shales. This method supported interpretation in this field where the reservoirs' sandstones and 
shales cannot be distinguished from the P- impedance alone. Using the simultaneous inversion results, we were able to achieve the desired discrimination by exploiting the contrast in sandstone-shale rigidity.

Most recently developed procedures for estimation of lithology and fluid content use concurrent information about both the compressional and shear properties of the reservoir rocks. The shear velocity or impedance is relatively insensitive to fluid content, but the shear modulus $\mu$ is a measure of the lithology (a combination of the sand/shale ratio and the porosity); with sand having a higher $\mu$ than shale. For a given lithology/porosity, the incompressibility $\lambda$ depends on the fluid content, with gas having lower $\lambda$ than water. Thus, a search for high quality hydrocarbon reservoirs (for instance, with high porosity sand) is often equivalent to finding zones of low $\mathrm{V}_{\mathrm{p}} / \mathrm{V}_{\mathrm{s}}$.

RockTrace AVO inversion was performed using the partial angle stacks. We used the original approach by $[1,10]$ and also adopted by[11,12]. From the well log data we crossplotted $\lambda \rho$ versus $\mu \rho$ for fluid discrimination or threshold type stack that isolates only the anomalous gas zones from background relationship. We took advantage of this petrophysical analysis of the well log data to determine exactly where within the crossplot different lithologiesand fluids will appear, including complex lithologies. By this procedure, each lithology was defined from the well logdata in terms of its $\lambda-\mu-\rho$ response. This was directly calibrated to well control to accurately represent the various lithologies and fluids present.

\section{Analysis and discussions}

The analysis given by [1] relied fundamentally on $V_{p}, V_{s}$ and $\rho$ variations, thus masking the original modulus parameterization, such as the more physical insight afforded by rigidity $(\mu)$. The link between velocity and rock properties for pore fluid detection is through the bulk modulus $(\mathrm{K})$ that is embedded in $\mathrm{V}_{\mathrm{p}}$. However, both $\mathrm{K}$ and $\mathrm{V}_{\mathrm{p}}$ have the most sensitive pore fluid indicator $\lambda$, as shown by the relationships given thus:

$$
V_{p}^{2}=(\lambda+2 \mu) / \rho=(K+(4 / 3) \mu) / \rho
$$

$$
V_{s}^{2}=\mu \rho
$$

The emphasis here is to use moduli and density relationships to velocities $\left(V_{p}, V_{s}\right)$ or impedances $\left(Z_{p}\right.$, $\mathrm{Z}_{\mathrm{s}}$ ) given as: $\mathrm{P}$-impedance:

$$
Z_{p}^{2}=\left(\rho \cdot V_{p}\right)^{2}=(\lambda+2 \mu) \rho
$$

(3)

and S-impedance:

$$
Z_{s}^{2}=\left(\rho . V_{s}\right)^{2}=\mu \rho
$$

In order to extract the orthogonal Lame parameters $\lambda$ and $\mu$ from the logs with measured density $\rho$ or $\lambda \rho$ and $\mu \rho$ from seismic without known density.Thus:

$$
\begin{aligned}
& \lambda=V_{p}{ }^{2} \cdot \rho-2 V_{s}^{2} \cdot \rho \\
& \ldots \ldots \ldots \ldots \ldots \ldots \ldots \ldots \ldots \ldots \ldots \ldots \ldots \ldots \\
& \mu
\end{aligned}
$$

(6)

$$
\lambda \rho=Z_{p}^{2}-2 Z_{s}^{2}
$$$$
\mu \rho=Z_{s}^{2}
$$

Because of $V_{p}$ 's dependence on both $\lambda$ and $\mu$, the effect of decreasing $\lambda$ is a direct response of the gas porosity is almost completely offset by an increase in $\mu$ in going from capping shale to gas sand. However, for surface seismic without an independent measurement of density, the extraction of $\lambda$ and $\mu$ is not possible with any certainty.

Now we demonstrate how the $\lambda$ - $\mu$-pcrossplot analysis and inversion volumes were used to discriminate lithologies and fluids in Amangi field.The " $\lambda$ " term, or incompressibility, is sensitive to pore fluid, whereas the " $\mu$ " term, or rigidity, is sensitive to the rock matrix. It is impossible to de-couple the effects of density from " $\lambda$ " and " $\mu$ " when extracting this information from seismic data. It is therefore beneficial to crossplot $\lambda \rho v e r s u s ~ \mu \rho$, to minimize the effects of density [13]. 
From AVO inversion results at the wells, we obtained $\mu$, and $\lambda$, and combining them with the $\rho$ we obtained $\mu \rho$ and $\lambda \rho$, which are useful in distinguishing sand quality and fluid content. The subject of the $\mu \rho$ and $\lambda \rho$ helps in understanding the AVO response because they are fundamental concepts which could be considered independent and interpreted separately and in combination to provide additional information on the nature and content of the reservoir rocks and fluids.

Fig.5show the crossplot of these properties, and we observed that since gas compress easily, the presence of gas in sandstone (gas sand), causes a significant decrease in its incompressibility. Gas in sand does not affect its rigidity but sand has high rigidity, so the result is a significant AVO response which depends on the contrast between incompressibility and rigidity as observed in the $\lambda \rho-\mu \rho$ space.
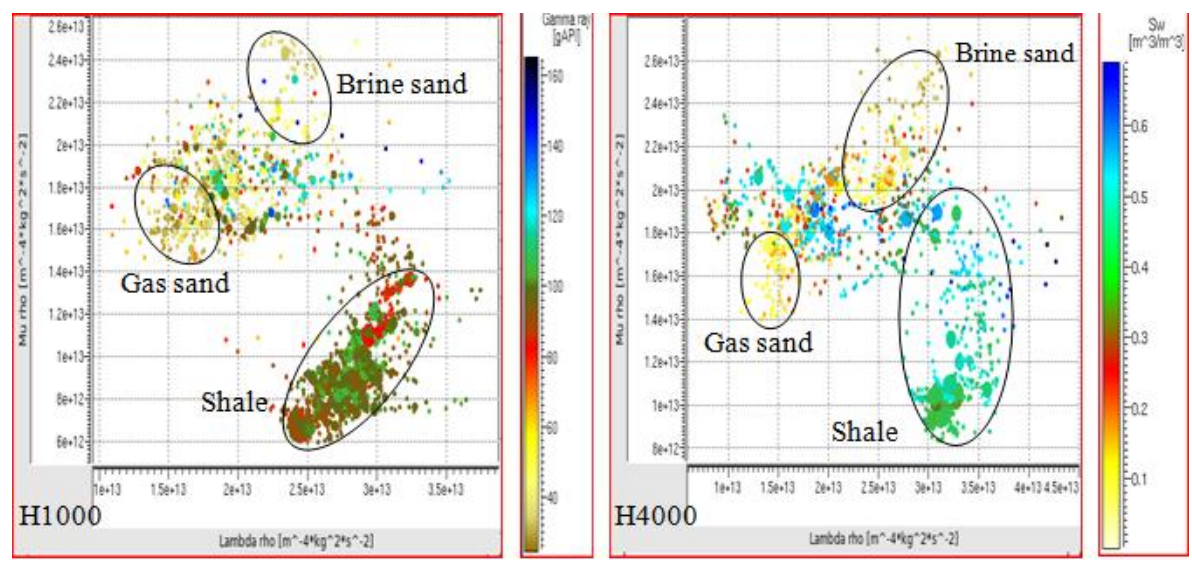

Figure 5.Crossplots between Lambda-rho and Mu-rho for H1000 and H4000, colour-coded to gamma ray and water saturation.

An effective fluid indicator can be found on a crossplqfof $\lambda \rho=Z_{\mathrm{s}}{ }^{2}$ versus $\mu \rho=\mathrm{Z}_{\mathrm{p}}{ }^{2}-2 \mathrm{Z}_{\mathrm{s}}{ }^{2}$. The intuitive interpretation of this is that $\lambda \rho$ and $\mu \rho$ are fundamentally more orthogonal than $P$-impedance $\left(Z_{p}\right)$ and $S$ impedance $\left(Z_{s}\right)$, stemming from the ambiguity in the $V_{p}$ and $V_{s}$ relationships that share the same value of rigidity $\mu[14]$.

In Fig. 6, we observed that both $\mu \rho$ and $\mathrm{V}_{\mathrm{p}} / \mathrm{V}_{\mathrm{s}}$ spaces could also discriminate litho-fluids in the area, as high $\mu \rho$ and low $V_{p} / V_{s}(1.8)$ indicate gas sand while higher $V_{p} / V_{s}(1.8-2.4)$ value indicate shale. There is some level of overlap in the values of the $\mathrm{V}_{\mathrm{p}} / \mathrm{V}_{\mathrm{s}}$ ratio and $\mu \rho$ of the gas sands and brine sands as we could see from the crossplots.
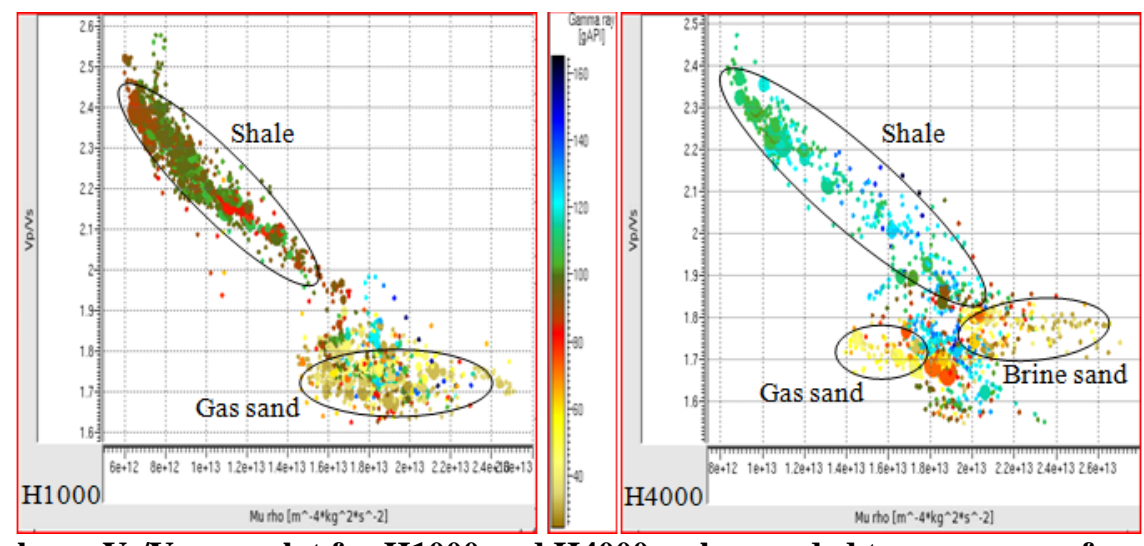

Figure 6. Mu-rho vs $\mathrm{V}_{\mathrm{p}} / \mathrm{V}_{\mathrm{s}}$ crossplot for $\mathrm{H1000}$ and $\mathrm{H4000}$, colour coded to gamma ray for quick lithology identification.

The impedance volumes were converted to Lamé's parameter volumes to estimate other geophysical parameters which might optimally discriminate between lithologies and fluids. Although, in this regard, we found theLamé's parameters, $\lambda$ and $\mu$ particularly useful, the product of these with density was actually computed. From the well log analysis made earlier, we expect that reservoir sandstones should have lower $\lambda$ and higher $\mu$.

Fig.7 shows $\lambda \rho$ volume from the acoustic impedance inversion with $\lambda \rho$ volumes from some of the wells, well-002, well-003 and well-004 inserted in colour and the tops of well-001 and Well-005 also. Low $\lambda \rho$ 
values are seen along the well trend and in some other off-well regions which are interpreted to indicate gas filled sands with high porosity.

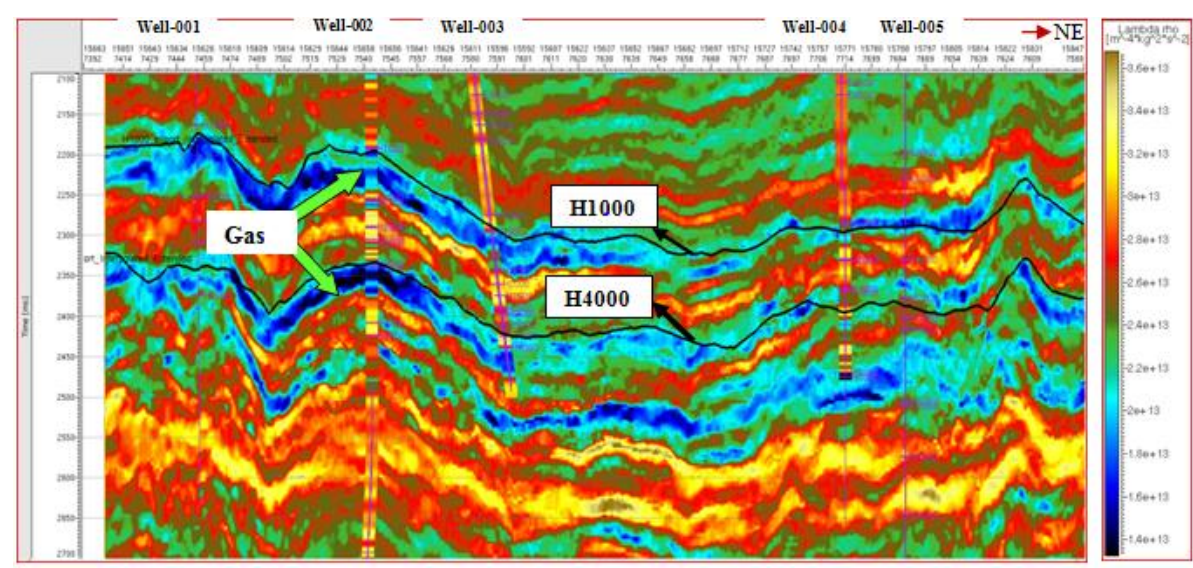

Figure 7. Lambda-Rho volume obtained from the inverted impedance volume overlain with tops Lambda-Rho section from the wells in the study area. Low Lambda-Rho indicates gas sand and high MuRho indicates lithology. Therefore Lambda-Mu-Rho is a good litho-fluid discriminator in this field.

In Fig.8, the large $\mu \rho$ values along the well trend and off-well regions imply highly rigid facies which areconsistent with sandstones. The wells (well-001, well-005 and well-004) displayed gamma ray logs while $\mu \rho$ $\log$ is inserted in well-002 and well-005 is the inverted (smoothed density) volume from the well. All show a good match with the inverted volume. The facies should exhibit both high $\mu \rho$ and low $\lambda \rho$ as expected and we are interested in data points which satisfy both of these conditions. The colour coding simply identifies regions in the volumes which consist of the same values.

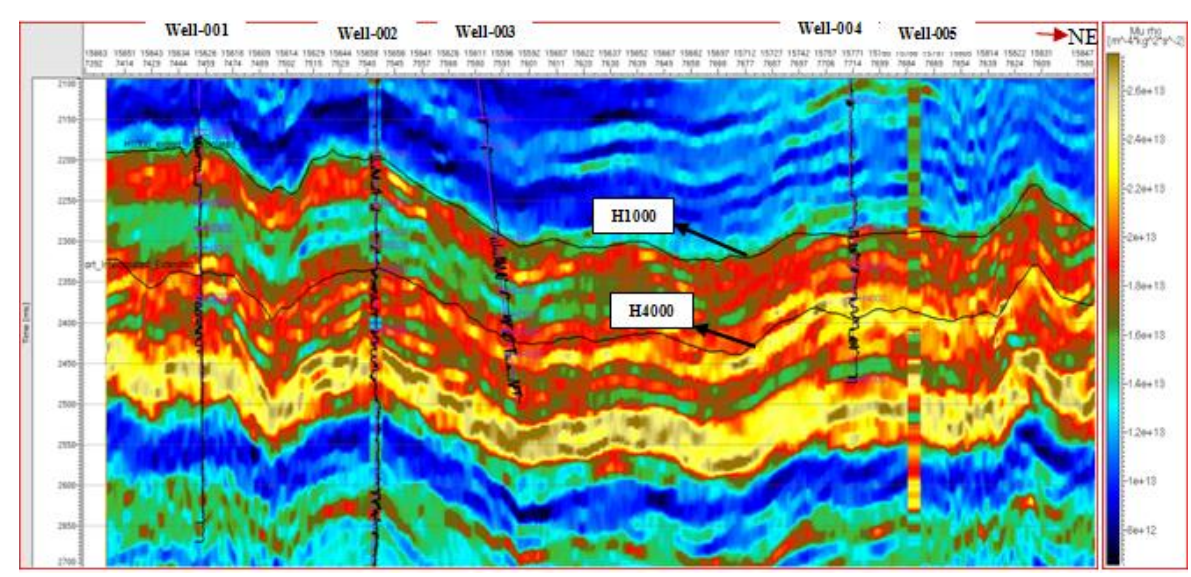

Figure 8.Mu-Rho volume with gamma ray log and inverted Mu-Rho from wells overlain, show well markers (tops) in well-001, a gamma ray log in well-004 and impedance logs in the rest of the wells.

\section{Conclusions}

Firstly, since the well logs can differentiate the gas zones with these attributes theprestack seismic inversion is also a useful product for interpretation as expected. This is because if well logs can't separate gas zones then seismic attributes also may not be able to do that.Secondly, the above attributes satisfactorily differentiatedgas zones from their surrounding geology, but could not quantify the uncertainty associated with reservoir quality and dissolved or fizz water. Thirdly, these attributes became more predictable and reliable with the availability of sufficient sidewall samples as this gave accurate dry bulk and shear moduli values, though understanding the relationships of these attributes with non-fluid indicator gas reservoirs or transparent sections is still a subtle challenge.

Thus, the method provided a direct and improved petrophysical discrimination of rock properties using the $\lambda \rho$ and $\mu \rho$ over conventional $V_{p}, V_{s}$ or $Z_{p}$ and $Z_{s}$ analysis. The good correlation of theresults of the $\lambda \rho$ and $\mu \rho$ inversionvolumes with those of rock physics analysis observedat the wells provided confidence in our interpretationof hydrocarbon potential away from the wells. Also we have greater physical insight into the Lamé's parameters in terms of their seismic responses by isolating reservoir rock properties for pore fluid and lithology. Also, we discovered easier AVO crossplotthresholding for a more sensitive $\lambda \rho, \mu \rho$ fluid detection and 
a new pure $\lambda \rho$ section showing gas zones. As a result this method provided a more accurate detail of porosity and fluid saturation, with sufficient well calibration.

Therefore, $\lambda-\mu-\rho$ technique is one example of how interpreters are using advanced AVO analysis to identify hydrocarbons and reservoir rocks. It involves crossplotting or interpretation of multiple volumes of data to correctly interpret lithologies and fluids. The $\lambda-\mu-\rho$ technique was able to identify gas sands, because of the separation in responses of both the $\lambda \rho$ and $\mu \rho$ sections to gas sands versus shale. Many different lithologies could also be identified by the crossplot of $\lambda \rho$ versus $\mu \rho$. This is possible because each lithology has a different rock properties response subject to fluid content and mineral properties.

\section{Acknowledgements}

Theauthorsgratefully thank the Shell Petroleum development Company (SPDC) of Nigeria, for granting us the permission to publish this work. We also thank Dike S. Robinson, Francesca I. Osayande, PrahladBasak, Temitope J. Jegede and Reginald I. Mbah for their immense contributions.

\section{References}

[1]. B. Goodway, T. Chen and J. Downton, Improved AVO fluid detection and lithology discrimination using Lame petrophysical parameters: " $\lambda \rho$ ", " $\mu \rho$ " and " $\lambda / \mu$ fluid stack", from $\mathrm{P}$ and $\mathrm{S}$ inversions, Canadian Society of Exploration Geophysicists Recorder, 1997, $3-5$.

[2]. J. Pendrel, and P. van Riel, Estimation and interpretation of P- and S- impedance volumes from simultaneous inversion of P-wave offset seismic data, Society of Exploration Geophysicists, Expanded Abstracts, 2000, 1 - 4.

[3]. P. F. Anderson, and F. D. Gray, Using LMR for Dual Attribute Lithology Identification, San Antonio, Main Menu, Society of Exploration Geophysicists, Expanded Abstracts, 2001, $1-2$.

[4]. G. B. Madiba, and G. A. McMechan, Processing, inversion, and interpretation of a 2D seismic data set from the North Viking Graben, North Sea, Geophysics, 68(3), 2003, 837 - 848.

[5]. S. Samantaray, and P. Gupta, An interpretative approach for gas zone identification and lithology discrimination using derivatives of $\lambda *$ pand $\mu *$ pattributes, $7^{\text {th }}$ Biennial international Conference and Exposition on Petroleum Geophysics, "HYDERABAD 2008", Society of Petroleum Geophysicists, 2008, 386-341.

[6]. H. Feng, B. H. Russell, and J. C. Bancroft, A comparison of hydrocarbon indicators derived from AVO analysis, Consortium for Research in Elastic Wave Exploration Seismology Research Report,19, 2007, Pp. 1 - 9.

[7]. K. C. Short and A. J. Stauble, Outline of geology of Niger Delta,TheAmerican Association of Petroleum Geologists Bulletin, 51(5), 1967, $761-799$.

[8]. M. L. W. Tuttle, R. R. Charpentier, and M. E. Brownfield, The Niger Delta Petroleum System, Niger Delta Province, Nigeria, Cameroun and Equatorial Guinea, US Geological Survey, Denver, Colorado, United States of America, 1999, 6 - 29.

[9]. H. Doust, and E. Omatsola, Niger Delta, divergent/passive margin basins, American Association of Petroleum Geologists Memoir48, 1990, $239-248$.

[10]. S. Pochat, S. Castelltort, J. Van Den Driessche, K. Besnard, and C. Gumiaux, A simple method of determining sand/shale ratios from seismic analysis of growth faults: An example from upper Oligocene to lower Miocene Niger Delta deposits, TheAmerican Association of Petroleum Geologists Bulletin, 88(10), 2004, 1357 - 1367.

[11]. R. M. Bustin, Sedimentology and characteristics of dispersed organic matter in Tertiary Niger Delta: origin of source rocks in a deltaic environment, The American association of Petroleum Geologists Bulletin,72(3), 1988, 277 - 298.

[12]. J. I. Nwachukwu, and P. I. Chukwura, Organic matter of AgbadaFormation, Niger Delta, Nigeria,The American Association of Petroleum Geologists Bulletin, 70(1), 1986, 48 - 55.

[13]. P. Stacher, Present understanding of the Niger Delta hydrocarbon habitat, (in Tuttle; Tertiary Niger Delta Petroleum System, Niger Delta Province), United States Geological Survey Open-File Report, 1995, 99-50-H.

[14]. L. M. Omudu, J. O. Ebeniro, M. Xynogalas, N. Osayande, and S. Olotu, Fluid discrimination and reservoir characterization from onshore Niger Delta, Annual General Meeting, Las Vegas, Society of Exploration Geophysicists, 2008, 2001 - 2005. 